\title{
SMK1, a developmentally regulated MAP kinase, is required for spore wall assembly in Saccharomyces cerevisiae
}

\author{
Lisa Krisak, ${ }^{1}$ Randy Strich, ${ }^{3}$ R. Scott Winters, ${ }^{1}$ J. Perry Hall, ${ }^{1}$ Michael J. Mallory, ${ }^{3}$ David Kreitzer, ${ }^{2}$ \\ Rocky S. Tuan, ${ }^{1,2}$ and Edward Winter ${ }^{1,4}$ \\ ${ }^{1}$ Department of Biochemistry and Molecular Biology, ${ }^{2}$ Department of Orthopaedic Surgery, Thomas Jefferson University, \\ Philadelphia, Pennsylvania 19107 USA; ${ }^{3}$ Fox Chase Cancer Center, Philadelphia, Pennsylvania 19111 USA.
}

\begin{abstract}
Mitogen-activated protein (MAP) kinases comprise a family of conserved, eukaryotic enzymes that mediate responses to a wide variety of extracellular stimuli. In yeast, different signal transduction pathways utilize distinct MAP kinase family members. We have identified a new yeast MAP kinase gene (named SMK1) that is required for the completion of sporulation. Molecular and cytologic markers indicate that meiotic development proceeds normally in homozygous smk1-A1 diploids through meiosis II. However, light and electron microscopy show that smk1 asci are defective in organizing spore wall assembly. Consistent with a

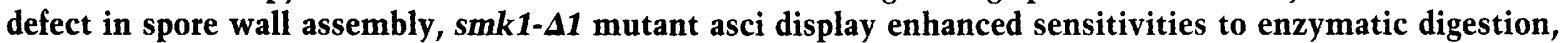
heat shock, and exposure to ether. SMK1 mRNA, which is not detectable in vegetative cells, is derepressed at least 200-fold just prior to prospore enclosure. We propose that the SMK1 MAP kinase participates in a developmentally regulated signal transduction pathway that coordinates cytodifferentiation events with the transcriptional program.
\end{abstract}

[Key Words: MAP kinase; sporulation; yeast]

Received June 3, 1994; revised version accepted July 22, 1994.

Mitogen-activated protein (MAP) kinases comprise a family of conserved signal-transducing enzymes that are responsible for phosphorylating regulatory molecules. MAP kinases are activated through upstream cascades of conserved kinases. The activation of these upstream cascades can be triggered by diverse signaling molecules including receptor tyrosine kinases, G-proteins, RAS, and protein kinase $\mathrm{C}$ (for recent reviews see Crews and Erickson 1993; Errede and Levin 1993; Neiman 1993; Nishida and Gotoh 1993; Ammerer 1994; Marshall 1994). Once activated, MAP kinases phosphorylate regulatory molecules, including transcription factors and components of the cell-cycle machinery, thereby effecting changes in gene expression and proliferative activity.

In the budding yeast, four different MAP kinase signaling pathways have been described: the mating-pheromone response pathway, the pseudohyphal differentiation pathway, the osmoregulatory pathway, and the protein kinase C response pathway (for review, see Ammerer 1994). The mating-pheromone response pathway is understood most thoroughly and represents a paradigm for the molecular mechanisms that mediate signaling (for review, see Sprague and Thorner 1992). The response of haploid cells to mating pheromone requires

${ }^{4}$ Corresponding author. the partially redundant MAP kinases Fus3 and Kss1, which are activated by the dual specificity threonine/ tyrosine-specific MAP kinase kinase, Ste7. The Ste7 kinase is itself activated by the MAP kinase kinase kinase, Stel1. Upstream members of the mating response pathway that communicate the signal initiated by pheromone/receptor interaction to Stell activation include the Ste20 kinase, Ste5 /which has no known enzymatic activity), and a heterotrimeric G-protein. Downstream targets of Fus3 and Kss1 include the Ste12 transcription factor, which activates pheromone-responsive genes, and the Farl protein, which inhibits cell-cycle progression (for review, see Sprague and Thorner 1992). The diploidspecific pathway that mediates the dimorphic switch to pseudohyphal/filamentous growth (Gimeno et al. 1992) shares the upstream kinases (STE7, STE11, and STE20) and the Ste12 transcription factor with the mating-pheromone response pathway. It is likely that this dimorphic-switch pathway requires an additional pathwayspecific MAP kinase family member because fus $3 \mathrm{kss} 1$ double mutants still form pseudohyphae (Liu et al. 1993). The osmoregulatory pathway requires the MAP kinase family member, Hogl, which is activated in response to increased extracellular osmolarity by the Ste 7 homolog, Pbs2 (Brewster et al. 1993). The protein kinase C response pathway requires the Ste11 homolog, Bck1 (also known as Slk1), the functionally redundant Ste7 ho- 
mologs, Mkk1 and Mkk2, and the MAP kinase Mpk1 (also known as Slt2) (Irie et al. 1993; Lee et al. 1993).

In contrast to budding yeast, which utilize separate MAP kinases for different signaling pathways, metazoans may target one or a few MAP kinases for responses to a variety of signals. For example, receptor tyrosine kinases may activate one MAP kinase isoform through the activation of Raf and MAP kinase kinase, but this same isoform may also be activated by a G-protein/protein kinase $\mathrm{C}$ cascade that acts through MAP kinase kinase kinase (Lange-Carter et al. 1993). Genetic studies in Drosophila have clearly shown that the MAP kinase homolog, rolled, mediates signaling through the epidermal growth factor (EGF) receptor homolog, as well as the sevenless and torso receptor tyrosine kinases (Biggs et al. 1994; Brunner et al. 1994). Thus, there must be additional levels of control that are expressed during development and differentiation that restrict MAP kinase activity to the appropriate cell types and/or establish specificity in MAP kinase-mediated responses.

Diploid yeast can exist in three distinct states. Vegetative growth occurs when sufficient sources of environmental carbon and nitrogen are present. Under conditions of limiting nitrogen, diploid cells undergo a dimorphic switch and assume pseudohyphal growth characteristics (Gimeno et al. 1992). When deprived of both nitrogen and a fermentable carbon source, diploids will exit the mitotic cell cycle and enter meiosis and spore development (for review, see Esposito and Klapholz 1981; Malone et al. 1991: Honigberg et al. 1993; Mitchell 1994). The process of meiosis and spore formation deviates significantly from the vegetative cell cycle. Following an elongated $S$ phase that does not require Cdc28 $p^{\text {cdc2/p34 }}$ kinase (Shuster and Byers 1989), synaptonemal complexes are observed as chromosomes pair prior to recombination. Chiasmata generated by recombination are necessary for the correct disjunction of homologs (i.e., the reductional division), marking the end of meiosis I. Without an intervening $S$ phase, a second round of mitotic-like (equational) chromosome segregation occurs that separates the sister chromatids to produce haploid genomes (meiosis II). The four haploid nuclei, which still remain within a single nuclear membrane, are then enveloped by the double membraneous prospore wall that appears to arise from the coalescence of vesicles near the spindle pole bodies (Byers 1981). The spore wall is then deposited from the space between the layers of the prospore wall (for review, see Byers 1981; Esposito and Klapholz 1981). The final differentiated spore wall consists of four layers. The two inner layers are closely juxtaposed and appear indistinguishable from the vegetative cell wall when examined by electron microscopy. The third layer is a spore-specific structure that is composed primarily of chitosan and chitin (Briza et al. 1988). The outermost electron-dense layer is the dityrosine coat (Briza et al. 1990b). The genes required to execute these landmark meiotic events exhibit a tight temporal expression pattern and have been classified accordingly as early, middle, and late (for review, see Magee 1987; Mitchell 1994).
In this report we describe the isolation and charcterization of a new MAP kinase gene named SMK1 (sporulation MAP kinase). SMK1 expression is tightly regulated with respect to the expression of sporulation-specific genes, and smk1 mutants are defective in spore wall assembly. The results indicate that a developmentally regulated transcriptional program is coupled to signaling events that coordinate cytodifferentiation.

\section{Results \\ Isolation of a new MAP kinase family member}

Polymerase chain reactions (PCRs), using oligonucleotide primers corresponding to highly conserved MAP kinase-specific domains, were performed on DNA extracted from yeast strains deleted for known MAP kinases (see Materials and methods). PCR products of the appropriate size were subcloned into plasmid vectors, and their nucleotide sequences were determined. One of the fragments encoded a protein that was similar to all known MAP kinases. This fragment was used as a hybridization probe to isolate the complete coding sequence from a yeast genomic library, and the gene was sequenced in its entirety. This gene, named SMK1, encodes a 388-residue protein that contains the 11 conserved subdomains shared by protein kinases and is most similar to MAP kinases (Fig. 1). Smk1 is $40 \%$ identical and $65 \%$ similar to the well-characterized mating-pheromone pathway MAP kinase, Fus3. In addition, Smkl shares comparable levels of similarity to the other yeast MAP kinases and to the mammalian Erk1. The conserved threonine and tyrosine residues corresponding to those phosphorylated in Fus3, Kss1, and Erk1 by their respective MAP kinase kinases, are present in Smk1. Therefore, by sequence criteria, SMK1 represents a member of the MAP kinase gene family. SMK1 was localized to chromosome XVI, proximal to MAK3 and NHP6, based on $273 \mathrm{bp}$ of overlapping nucleic acid sequence information (Tercero et al. 1992; Fig. 1).

\section{SMK1 is not required for vegetative growth or for known MAP kinase-mediated activities}

The StyI restriction endonuclease fragment that encodes amino acid residues 30-297 of the predicted SMK1 protein was replaced with the URA3 selectable marker in vitro to generate the plasmid pLAK46 (see Fig. 1; Table 2, below). This plasmid was subsequently used to replace the chromosomal SMK1 gene (yielding the smk1- $\Delta 1$ null allele) in various diploid strain backgrounds (see Table 1). Sporulation and microdissection of segregants from the smk1- $\Delta 1$ heterozygotes revealed no differences between the recovery of viable $s m k 1-\Delta 1$ and wild-type haploids. Thus, SMK1 is not required for vegetative growth or germination. The smk1- $\Delta 1$ disruption had no discernible effect on the ability of cells to grow on high osmolarity medium, on the ability of homozygous diploid mutants to undergo the dimorphic switch to pseudohyphal 
A

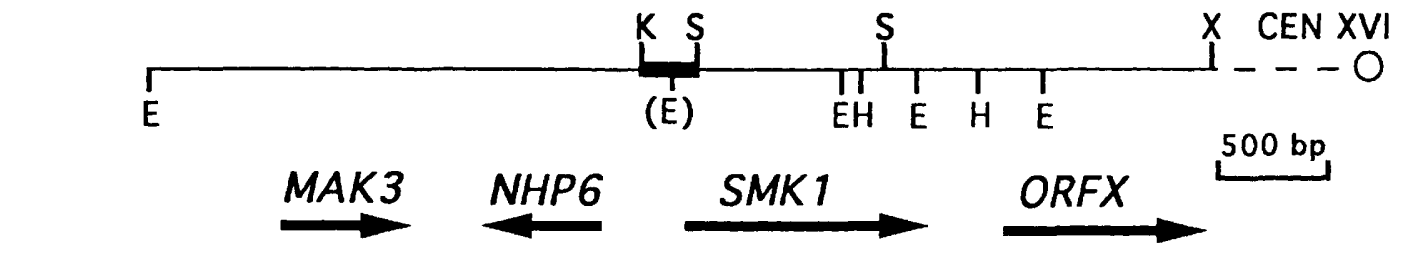

B

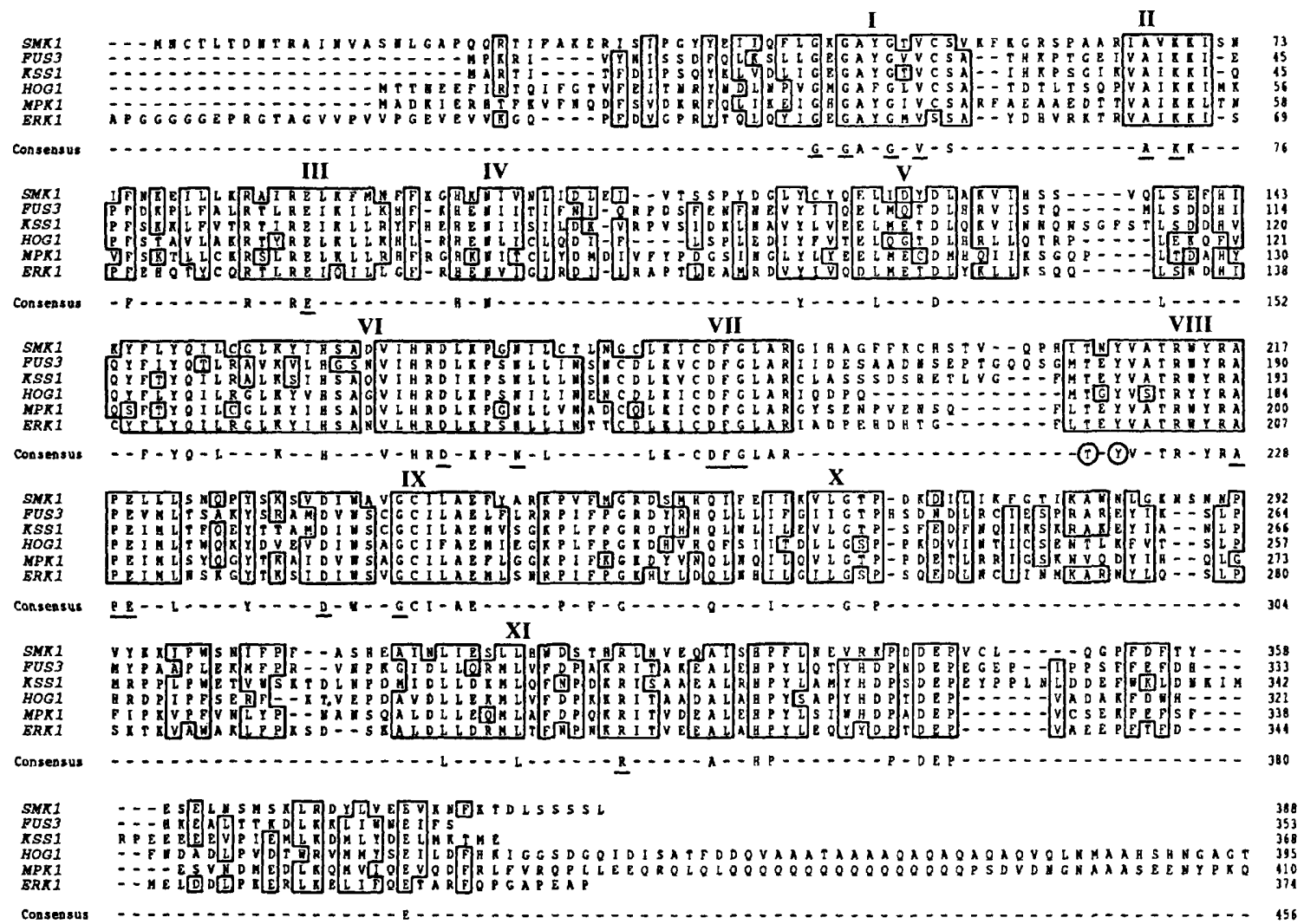

HOGI TG TORSDIAGGETGQRSCSCX
MPK1

${ }_{184}^{16}$

Figure 1. Chromosomal location, partial restriction endonuclease map, and amino acid sequence of $S M K 1$ compared with other MAP kinases. $(A)$ The $S M K 1$ locus of chromosome XVI. Protein-coding regions of the indicated genes are drawn to scale as arrows. The bold line represents the region of overlap between the nucleotide sequence reported in this study and the sequence reported by Tercero et al. (1992). The EcoRI and HindIII restriction endonuclease map shown below the line was generated from a composite file. The EcoRI site in parentheses is present in S288C strain backgrounds and absent in SK1 backgrounds. Restriction endonuclease sites used in the construction of plasmids are shown above the line and are not unique. Restriction endonuclease sites: $(\mathrm{E}) E c \mathrm{RI} ;(\mathrm{H}) \mathrm{HindIII}_{;}(\mathrm{K}) \mathrm{KpnI}_{\text {; }}$ (S) StyI; $(\mathrm{X})$ XhoI. ORFX shows an open reading frame that was discovered in this analysis that does not share a high degree of similarity with any proteins in the current data bases (see Materials and methods). (B) Comparison of the predicted amino acid sequence of Smk1 with known yeast MAP kinases Fus3, Kss1, Mpk1, Hog1, and Erk I from rat. Identical residues found in all six MAP kinases are shown as an underlying consensus. Similar residues are boxed. Amino acids found in almost all kinases are underlined. The tyrosine and threonine that are phosphorylated by MAP kinase kinases are circled. The subdomains (shown in Roman numerals) are as described by Hanks et al. (1988). The GenBank accession number for the SMK1 sequence is L35047.

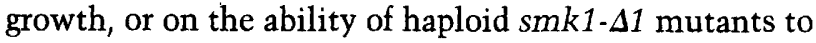
mate and form diploids (see Materials and methods). $S M K 1$ is therefore not required for activities mediated by known MAP kinase signaling pathways.
SMKl is required for ascospore development

A smk1-41 homozygous diploid (LAKY7) and an otherwise isogenic strain (YPH501) were transferred to sporu- 
Krisak et al.

Table 1. Yeast strains

\begin{tabular}{|c|c|c|}
\hline Strain ${ }^{a}$ & Genotype & Source \\
\hline JPHYl & $\begin{array}{l}\text { MATa ade2-1 can1-100 fus3::LEU2 his3-11,15 hog1::TRP1 kss1::HIS3 leu2-3,112 sst14 } \\
\text { trp1-1 ura3-1 }\end{array}$ & this study \\
\hline YPH501 & 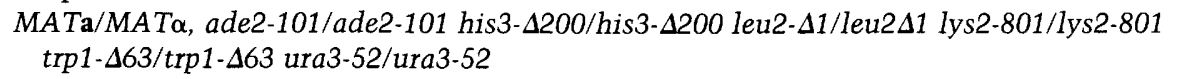 & $\begin{array}{l}\text { Sikorski and Hieter } \\
\text { (1989) }\end{array}$ \\
\hline LAKY1 & YPH501+smk1- $\Delta 1:: U R A 3 / S M K 1$ & this study \\
\hline LAKY7 & YPH501 + smk1- $11:: U R A 3 / s m k 1-\Delta 1:: U R A 3$ & this study \\
\hline CGX74 & MATa/MAT $\alpha$ trp1::HIS6/trp1::HIS6 ura3-52/ura3-52 & Gimeno et al. (1992) \\
\hline LAKY13 & CGX74 + smk1- $\Delta 1:: U R A 3 / s m k 1-\Delta 1:: U R A 3+p R S 314$ & this study \\
\hline NKY278 & MATa/MATa lys2/lys2 ura3/ura3 ho::LYS2/ho::LYS2 & Alani et al. (1990) \\
\hline LAKY30 & 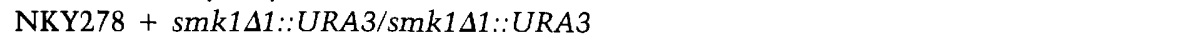 & this study \\
\hline LAKY57 & 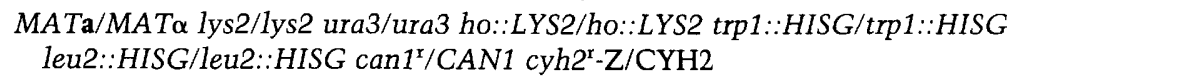 & this study \\
\hline LAKY58 & LAKY57 + smk1- $\triangle 1:: U R A 3 / s m k 1-\triangle 1: U R A 3$ & this study \\
\hline
\end{tabular}

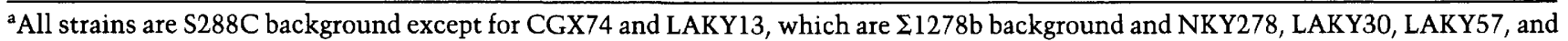
LAKY58, which are SKl background.

lation medium, and their ability to form normal ascospores was monitored by phase-contrast microscopy. In the wild-type YPH501 culture, 25-35\% of the cells formed mature ascospores. In contrast, no normal asci were observed in the mutant LAKY7 culture. Careful examination of the LAKY7 cells showed that some cells appeared to contain compartments suggestive of immature or disorganized ascospores (see below). However, no examples of mature asci, as evidenced by an organized tetrahedral array of birefringent spores, were observed. This sporulation defect was rescued by a single copy vector harboring SMK1 (pLAK51) but not by an otherwise identical plasmid lacking the SMK1 insert (pRS314). There were no differences in the yield or microscopic appearance of 4-spored asci when smk1- $\Delta 1 /$ SMK1 heterozygotes were compared with otherwise isogenic wildtype cells. Thus, the $\operatorname{smk} 1-\Delta 1$ allele is recessive and the defect in ascus development is not spore autonomous.

smk1- $\Delta 1$ mutants are blocked after meiosis but before spore wall assembly

To study the sporulation defect in more detail, the homozygous smk1- $\Delta 1$ mutation was introduced into the SK1 genetic background to yield strain LAKY30. SK1 diploids sporulate relatively rapidly and synchronously yielding greater than $90 \% 4$-spored asci. LAKY30 and the isogenic control strain NKY278 (see Table 1) were transferred to liquid sporulation medium, and aliquots of the culture were withdrawn at 2 -hr intervals. These cells were examined by phase-contrast light microscopy and by fluorescence microscopy of samples stained with the DNA-specific fluorophore, 4',6-diamidino-2-phenylindole dihydrochloride (DAPI). No cytological differences were observed between the NKY278 wild-type strain and the LAKY30 smk1- $\Delta 1$ mutant through the completion of the second meiotic division $10-8 \mathrm{hr}$ following transfer to sporulation medium). Both cultures stopped budding with indistinguishable kinetics (within $2 \mathrm{hr}$ after transfer to sporulation medium). DAPI fluorescence revealed that the appearance of bi- and tetranucleate cells (between 4 and $6 \mathrm{hr}$ ) was qualitatively and quantitatively indistinguishable between the wild-type and mutant cultures. These results indicate that smk1- $\Delta 1$ mutants initiated sporulation and completed meiosis I and II normally.

In wild-type cultures, prospores were delineated after 8 $\mathrm{hr}$, followed by the elaboration of the birefringent spore wall (10 and $12 \mathrm{hr}$, Figure 2A). In contrast, LAKY30 mutants appeared to separate the prospores inefficiently and failed to assemble spore walls. At the 10- and 12-hr time points, compartments in some mutant asci could be discerned (see Fig. 2C); but these compartments were irregular in size and shape, and an abnormally high percentage clustered in an unorganized manner. Occasionally, asci with four compartments organized in an apparently normal tetrahedral configuration could be seen (Fig. 2D). In all mutant asci, however, the normal birefringence characteristic of mature spore walls was absent. Moreover, little change in the LAKY 30 cells was observed in the 8- to 12 -hr time interval except for a moderate increase in ascal volume $(<1.5$-fold in mean diam.). The tetrahedral DAPI staining pattern in wild-type strains was indistinguishable at 12 and $24 \mathrm{hr}$ after the addition of sporulation medium (Fig. 2E,F), but the DAPI staining pattern in LAKY30 mutant asci appeared to become more irregular during this time, and the number of asci containing diffuse and extranumerary DAPI staining foci increased (Fig. 2G,H).

SMK1 is required for the normal expression of late, but not early or middle, meiotic genes

The consequences of the smk1- $\Delta 1$ deletion on the expression of a series of developmentally regulated genes was examined by $\mathrm{S} 1$ nuclease protection and Northern hybridization analyses. The expression of SPO13, SPO12, DIT1, and SPS100, which corresponds to early, middle, middle/late, and late meiotic genes, respectively, (for review, see Mitchell 1994), was compared in 

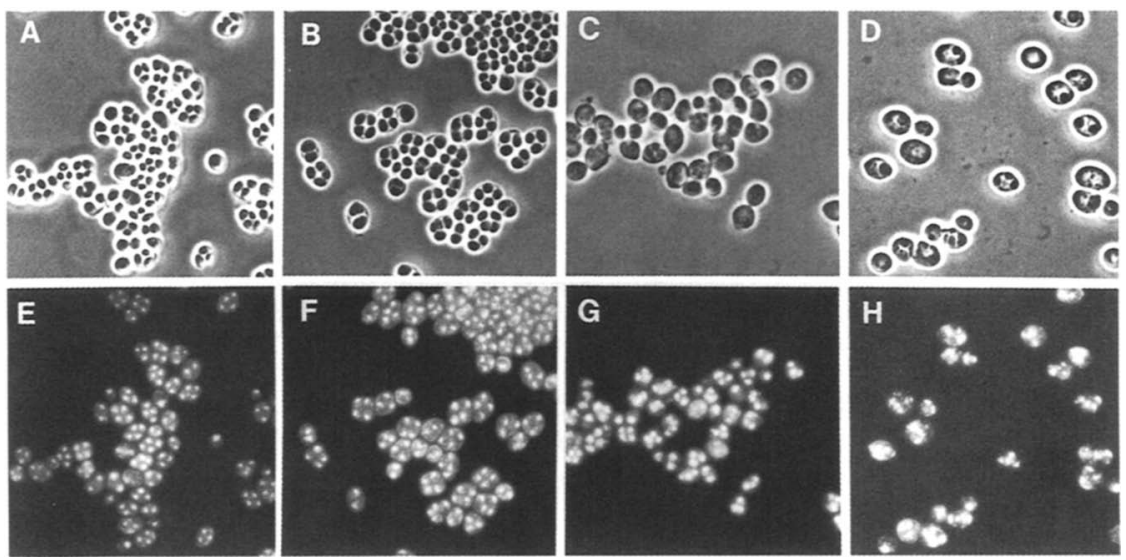

Figure 2. Microscopic appearance and localization of DNA in wild-type and $s m k 1$ mutant asci. $(A-D)$ Phase contrast photomicrographs; $(E-H)$ corresponding epifluorescence photomicrographs of DAPIstained asci. Wild-type asci $12 \mathrm{hr}\langle A, E|$, and $24 \mathrm{hr}(B, F)$ after transfer to sporulation medium exhibit indistinguishable, birefringent spore walls and characteristic tetranucleate organization. $s m k 1-\Delta 1$ mutant asci $12 \mathrm{hr}(C, G)$, and $24 \mathrm{hr}(D, H)$ after transfer to sporulation medium. Only a fraction of asci at both $12 \mathrm{hr}(C)$ and $24 \mathrm{hr}(D)$ contain spore walls that are discernible by phase-contrast microscopy. In those mutant asci that contain discernible spores, the organization is irregular. The smk1- $\Delta 1$ mutant asci are clearly tetranucleate $12 \mathrm{hr}$ after transfer to sporulation medium $(G)$, however, a percentage of the nuclei appear to become fragmented and the general appearance is more disorganized at $24 \mathrm{hrs}(H)$. sporulation time course assays between $s m k 1-\Delta l$ and wild-type cells (Fig. 3). The timing and relative expression levels of the early sporulation-specific gene SPO13, which is derepressed during the first meiotic prophase, and the middle sporulation-specific gene SPO12, whose mRNA levels peak following meiosis I chromosome disjunction, were indistinguishable between mutant and wild-type cells. These results are consistent with the microscopic observations that sporulation initiation and the execution of the meiotic landmark events are unaffected in smk1- $\Delta 1$ asci. The expression of DIT1, which is derepressed shortly after prospore enclosure, was reduced in the LAKY30 mutant to $25 \%$ of the wild-type level; however, the timing of DIT1 expression was similar in wild-type and mutant cells. SPS100 is expressed very late during ascal development and is required during the process of spore wall maturation (Law and Segall 1988). In the LAKY30 culture, SPS100 was expressed at $7 \%$ of the level found in wild-type asci. As observed with other genes, the timing of SPS100 expression was indistinguishable between $s m k 1-\Delta 1$ and wild-type asci. These results demonstrate that the pattern of sporulation-specific gene expression appears normal through meiosis, that postmeiotic sporulation-specific genes are expressed at lower levels in $s m k 1-\Delta 1$ mutants, and that this reduction becomes more severe at later time points.

\section{SMK1 is a middle sporulation-specific gene}

The phenotypic analysis of $s m k 1-\Delta 1$ mutants suggested that this MAP kinase functions between meiosis II and spore wall assembly. To determine whether this activity was being modulated at the level of SMK1 gene expression, SMK1 mRNA levels were monitored during sporulation by Northern analysis. SMK1 mRNA was undetectable in vegetative cells and shortly after transfer to sporulation medium. A dramatic increase in SMK1 transcript levels occurred in the middle period of sporulation, with maximal accumulation occurring near the 8 -hr time point when the majority of cells are completing meiosis II. This increase was followed by a rapid disappearance. SMK1 mRNA accumulation is contemporaneous with the accumulation of mRNA encoded by the middle sporulation-specific gene SPO12 (Fig. 3). Given the limits of detection, we estimate that the peak of SMK1 mRNA accumulation is at least 200-fold above the level found in vegetative cells. These results demonstrate that $S M K 1$ is a tightly controlled middle sporulation-specific gene and that its expression pattern coincides with the timing of the developmental block observed in $s m k 1-\Delta 1$ mutant asci.

\section{SMK1 is required for the assembly of functional spore walls}

The microscopic and molecular evidence suggest that smk1- $\Delta 1$ mutants are blocked in development before assembly of the spore wall. Normal asci, with mature functional spore walls, exhibit resistance to heat shock, ether, and enzymatic (glusulase) digestion. To determine whether smk1- $\Delta 1$ mutants assemble functional spore walls, wild-type and mutant asci were assayed for resistance to these various treatments. The plating efficiency of sporulated $s m k 1-\Delta 1$ mutants was reduced at least 5 orders of magnitude following a $40-\mathrm{min}, 55^{\circ} \mathrm{C}$ heat shock, at least 6 orders of magnitude following exposure to ether for $5 \mathrm{~min}$, and at least 2 orders of magnitude following glusulase digestion when compared with wildtype asci (Fig. 4, A, B, and C, respectively). Thus, by functional criteria, smk1- $\Delta 1$ asci are blocked in development before they assemble functional spore walls.

It was not possible to directly measure the viability of 


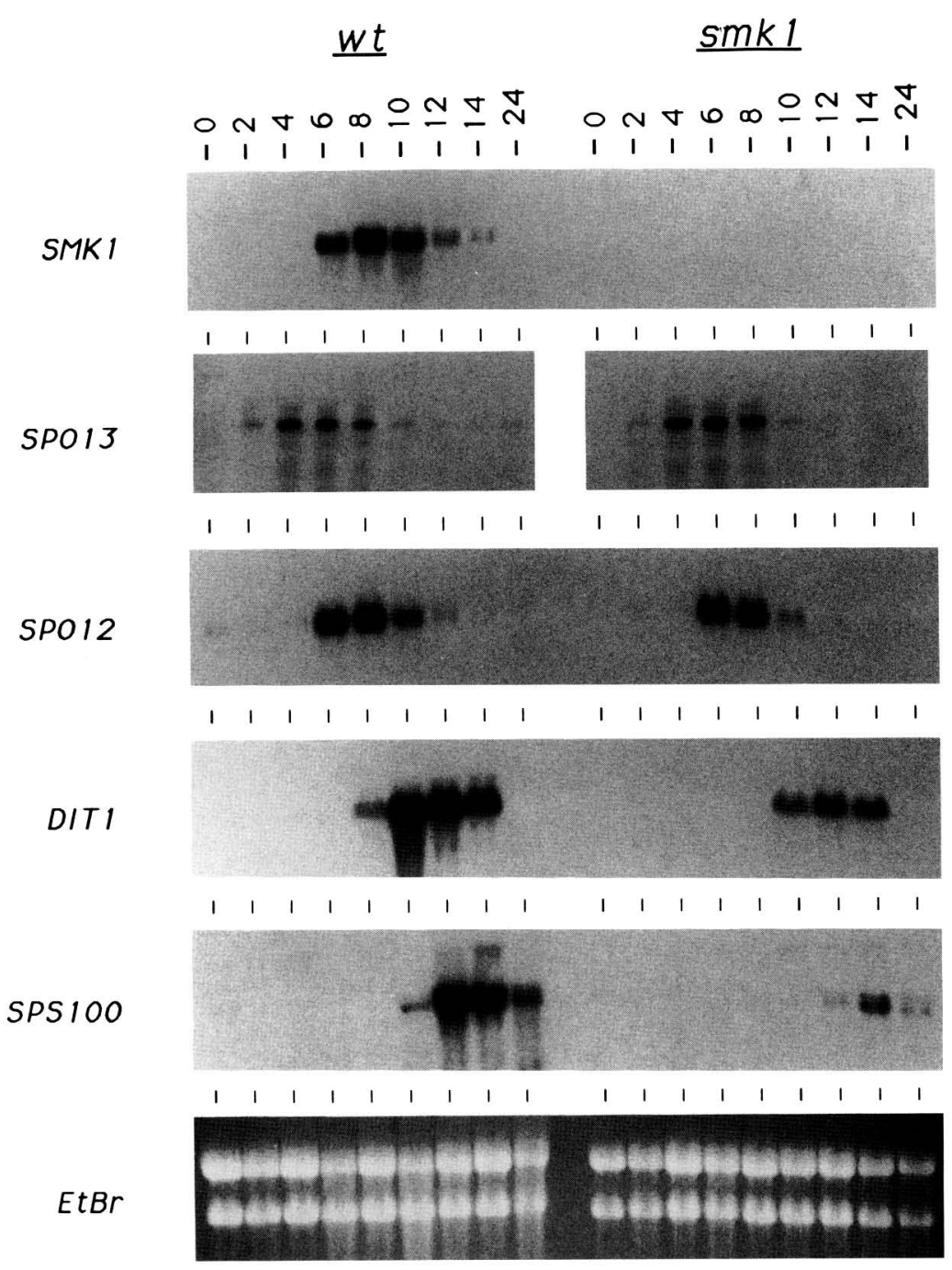

Figure 3. Sporulation-specific gene expression in wild-type and $s m k 1-\Delta 1$ mutant strains. Wild-type (wt) strain NKY278 and smk1- $\Delta 1$ mutant (smk1) strain LAKY30 were exposed to sporulation medium for the indicated number of hours before RNA was prepared. SPO13 mRNA levels were assayed by $\mathrm{S} 1$ nuclease protection, and $S M K 1$, SPO12, DIT1, and SPS100 mRNAs were monitored by Northern hybridizations of a single filter as described in Materials and methods. (EtBr) Ethidium bromide-stained agarose gel prior to transfer.

smk1- $\Delta 1$ meiotic products by methods that require their physical separation from the ascus, because smk1- $\Delta 1$ mutants are hypersensitive to enzymes that remove the ascal wall. When equal numbers of asci were plated directly onto rich medium, the colony-forming efficiency

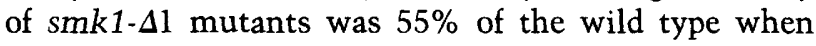
plated 1 day after transfer to sporulation medium and $18 \%$ of the wild type when plated 5 days after transfer to sporulation medium (Fig. 4D). In separate experiments, the percentage of can $1^{r}$ colonies derived from smk1- $\Delta 1 /$ smk1- $\triangle 1 \mathrm{Can} 1^{\mathrm{1}} / C A N 1^{\mathrm{s}}$ asci was identical to that derived from $S M K 1 / S M K 1$ can $1^{\mathrm{r}} / C A N 1^{\mathrm{s}}$ asci (see Materials and methods). These results are consistent with the normal

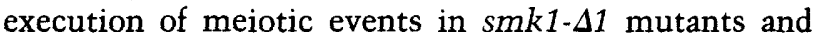
show that the meiotic products display a modest reduction in viability compared with wild type.

\section{SMK1 is required for the assembly of spore walls}

To assess the morphological and structural nature of the smk1- $\Delta 1$ spore-forming defect at high resolution, sporu- lated wild-type and mutant cultures were examined by transmission electron microscopy. The ultrastructure of a typical wild-type ascus is shown in Figure 5, A and B. Within the ascus, the spores are separated from the relatively content-free ascoplasm by the multilayered spore walls. The thin osmiophilic layer, which contains high amounts of dityrosine, surrounds the more diffuse and closely juxtaposed layer composed predominantly of chitin and chitosan (Briza et al. 1988, 1990a,b). These spore-specific structures surround the electron-lucent inner spore wall layers that appear identical to the cell wall found in vegetative cells (Fig. 5A,B).

Morphologically normal spore walls were not observed

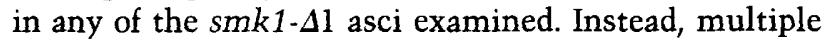
patterns of abnormal spore walls were observed. A single spore always appeared to be enveloped by a single spore wall pattern; however, multiple abnormal patterns were usually observed within a single ascus (see Fig. 5C-H). On the basis of ultrastructural appearance in terms of electron density, one class of mutant spore walls appeared to lack spore-specific structures entirely and con- 

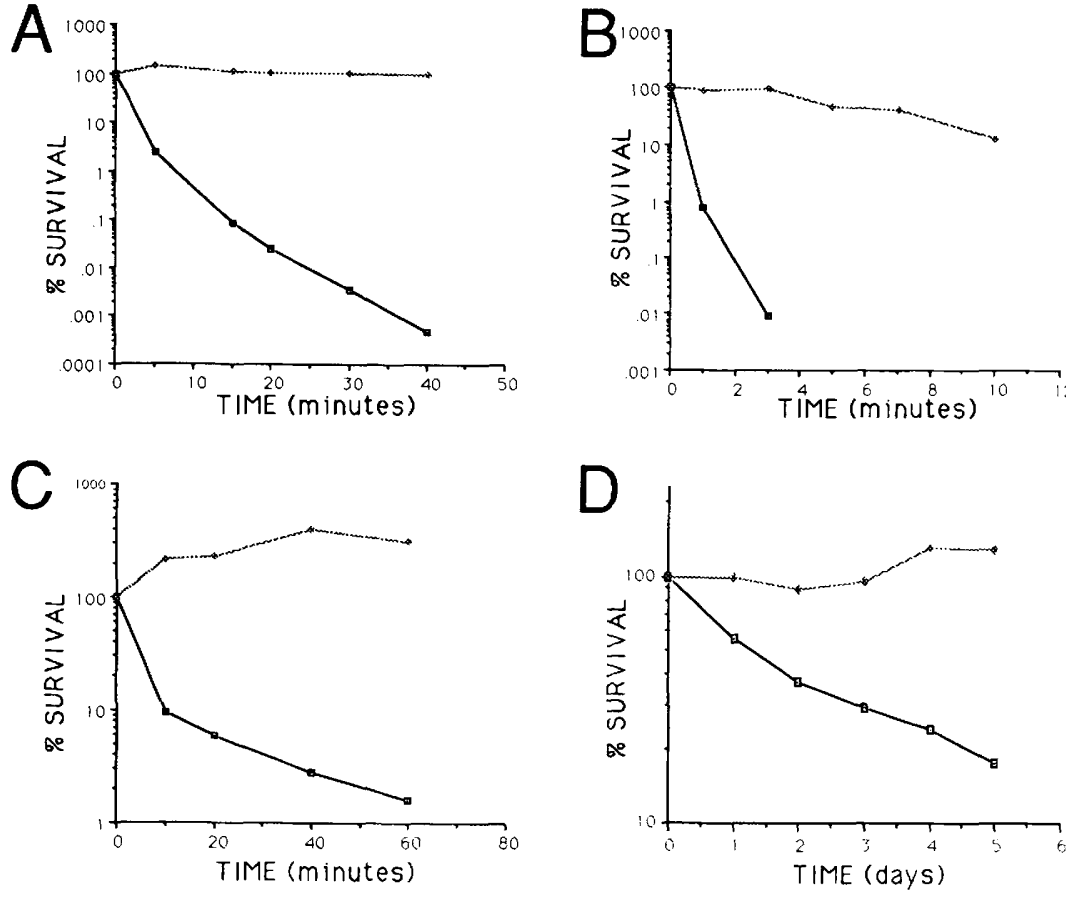

Figure 4. Resistance of wild-type and $s m k 1$ $\Delta 1$ asci following exposure to heat shock, ether, enzymatic (glusulase) digestion, or prolonged incubations in sporulation medium. Wild-type asci from strain NKY278 $(\diamond$, broken line) and $s m k 1-\Delta 1$ mutant asci from strain LAKY30 ( $\square$, solid line) were assayed for plating efficiency after exposure to $55^{\circ} \mathrm{C}(A)$, ether $(B)$, glusulase $(C)$ for the indicated times (see Materials and methods $)$. $(D)$ Cells were incubated in sporulation medium for the indicated times at $30^{\circ} \mathrm{C}$ before directly assaying plating efficiencies. In $B$, the recovery of smk1- $\Delta 1$ colonies exposed to ether for $>3 \mathrm{~min}$ was below the level of detection $\left(<1 \times 10^{-7}\right.$ survivors $)$. tained only the electron-lucent inner layers, whereas others appeared to contain only the electron-dense outer layers. Another class appeared to contain the inner and outer layers. In each of these cases, however, the order of these layers was reversed such that the inner electronlucent layers appeared to be on the outside. In other spores, multilayered structures that resembled various stages in prospore wall development were observed. Incomplete separation of adjacent spores was seen in a low percentage $(5-10 \%)$ of the specimens. In addition, in all smk1- $\Delta 1$ asci, substantial amounts of cytoplasmic components were seen in the ascoplasm as well as within the spores. The appearance of multiple spore wall layers, albeit in inappropriate orders, indicates that the spore wall components are synthesized in $s m k 1-\Delta 1$ mutants. The data suggest that $s m k 1-\Delta 1$ mutants are defective in coordinating the assembly of the spore wall.

\section{Discussion}

\section{Coordination of spore wall assembly processes by the Smk1 MAP kinase}

This study describes a developmentally regulated MAP kinase that is required for the completion of sporulation. The molecular, cytologic, ultrastructural, and functional characterization of smk1 mutants shows that SMK1 is required after meiosis but before spore wall assembly. This interval of development involves dynamic changes in gene expression, cellular organization, and assembly events that need to be coordinated by the ascoplasm. The ultrastructural analysis showed that the spore wall components are assembled in a variety of abnormal patterns in $s m k 1$ asci. Furthermore, individual spores are always surrounded by a uniform spore wall pattern, and multiple patterns can exist within a single ascus. It is likely that the presence of abnormal spore walls in $s m k 1-\Delta 1$ mutants represents the disruption of a complex, highly ordered pattern of nucleation and cooperative assembly processes.

Two possibilities could account for the uncoordinated spore wall assembly. First, spore wall components may be present in abnormal amounts in $s m k 1$ mutant asci. For example, $S M K 1$ may be required to activate late transcriptional activators (or inhibit repressors) of genes encoding spore wall components. Inappropriate amounts of critical spore wall components could lead directly to abnormally timed or localized nucleation and assembly processes culminating in the $s m k 1$ spore wall phenotype. This study, however, does not demonstrate that $S M K 1$ regulates the transcription of sporulation-specific genes. For example, the severe reduction of SPS100 expression, which is transcribed downstream of the SMK1 requirement (spore wall assembly vs. maturation), may represent a secondary phenotype resulting from the inability to assemble the spore wall correctly. The second possibility that could account for the uncoordinated spore wall assembly is that $s m k 1$ mutants are defective in regulating the machinery that assembles the spore wall components. The lack of coordination could reflect the inability of $s m k 1$ mutants to temporally couple critical assembly processes with the transcriptional program, or it could reflect the inability of $s m k 1$ mutants to synchronize multiple independent assembly processes. The above possibilities are not mutually exclusive. MAP kinases have been shown to regulate and coordinate multiple independent processes. For example, FUS3 si- 


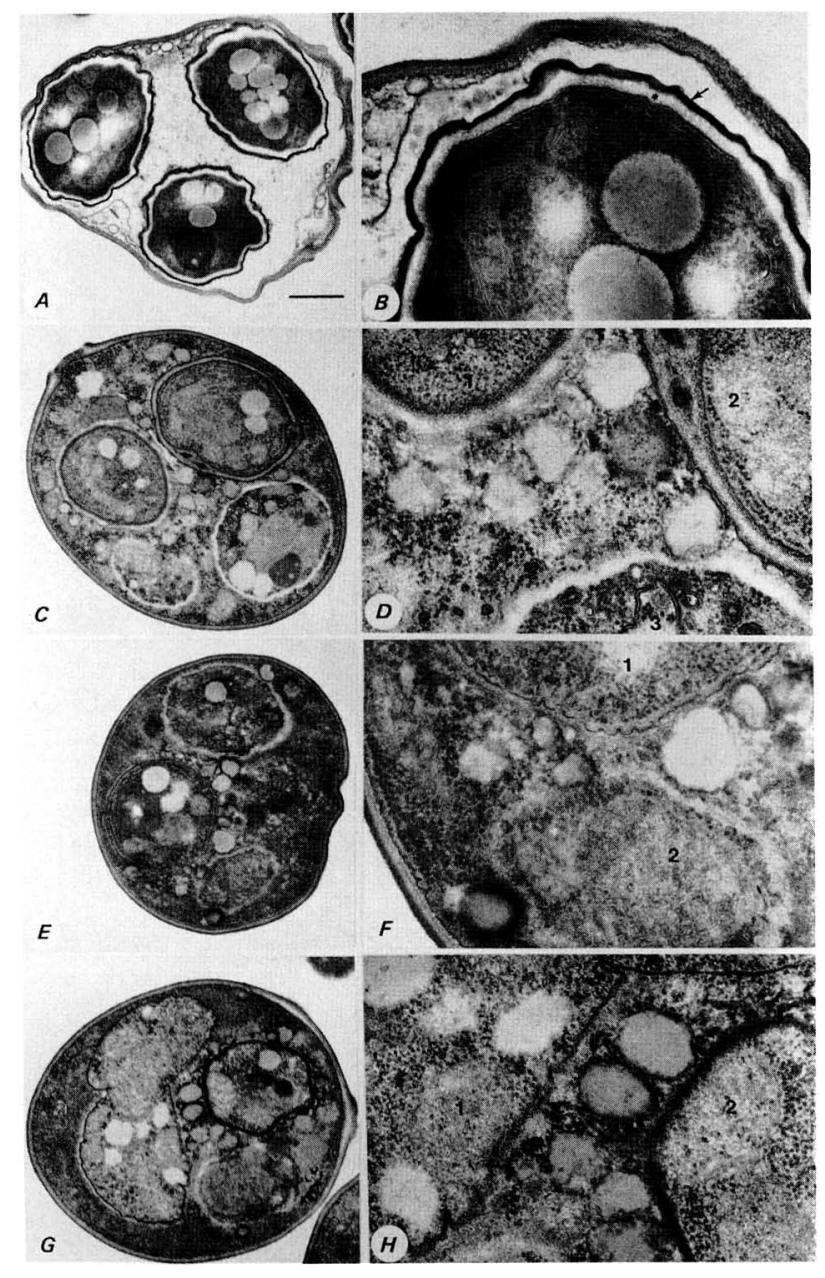

Figure 5. Ultrastructure of wild-type and $s m k 1-\Delta 1$ mutant asci. $(A, B)$ Wild-type strain NKY278; $(C-H)$ smk1- $\Delta 1$ mutant strain LAKY30. Specimens were fixed $18 \mathrm{hr}$ after transfer to sporulation medium. $(A, C, E, G)$ Low-magnification micrographs of single asci, $(B, D, F, G)$ corresponding higher magnifications of spore walls. In the wild-type ascus, well-defined spores are seen $|A|$, which are enclosed within spore walls $|B|$ consisting of the two inner, electron-lucent chitin/chitosan layers that appear as a single layer (asterisk) followed by the outer chitin/chitosan layer, which appears closely juxtaposed and only partially resolved from the electron-dense dityrosine coat (arrow). A variety of spore-wall defects are apparent in $s m k 1-\Delta 1$ mutant asci $(C-H) .(C, D)$ Spore 1 lacks the chitin/chitosan and dityrosine layers, spore 2 has a trilaminar structure that may represent a late stage in development of the prospore wall, and spore 3 has only the inner spore wall that directly surrounds the cytoplasm. $(E, F)$ Spore 1 displays an irregular structure that may represent an early stage in prospore wall development, and the cytoplasm appears barely contained within spore $2 .(G-H)$ Incomplete separation of the prospore is seen in spore 1 while spore 2 has only an electron-dense structure that may represent the outer spore wall layers. Scale bar, $1 \mu \mathrm{m}(A, C, E, G)$ and $0.33 \mu \mathrm{m}(B, D, F, G)$.

multaneously activates the expression of cell type-specific genes and negatively regulates cell-cycle progres- sion, thus coupling these otherwise independent processes in response to a single signal (Elion et al. 1993; Peter et al. 1993). The Smk1 MAP kinase might similarly regulate multiple processes required for spore maturation to assure that this complex window of ascal development proceeds in a coordinated fashion.

\section{Existence of additional components of the SMK1 MAP kinase pathway}

The high degree of similarity between Smk1 and other MAP kinases and the conserved nature of MAP kinasemediated signaling interactions imply that there are other members of this pathway. Recently, SPS1, which encodes a sporulation-specific gene that is derepressed during meiosis (Percival-Smith and Segall 1986), has been shown to encode a kinase that is $44 \%$ identical to Ste20. Homozygous sps1 mutants are blocked in sporulation between meiosis and spore maturation (Friesen et al., this issue). Therefore, it is likely that SPS1 and $S M K 1$ function in the same signaling pathway. MCK1 encodes a serine/threonine and tyrosine kinase that is required for chromosomal maintenance (Shero and $\mathrm{Hi}$ eter 1991), normal levels and kinetics of meiotic activation, as well as normal levels of ascal maturation (Neigeborn and Mitchell 1991). This latter phenotype raises the possibility that $M C K 1$ participates in the $S M K 1$ pathway. We have shown recently that a $42-\mathrm{kD}$ protein is tyrosine phosphorylated during spore wall maturation 8-10 hr after SK1 diploids are transferred to sporulation medium (J.P. Hall and E. Winter, unpubl.). This observation is consistent with the activation of Smk1 by a MAP kinase kinase. It is likely that additional signaling molecules are required for activation of the SMK1 MAP kinase pathway.

\section{Nature of the signal}

An unresolved issue concerns the nature of the primary signaling event that activates the SMK1 pathway. Previous studies have shown that once yeast cells execute the first meiotic division, they have passed a point termed commitment, after which they are no longer responsive to external stimuli (Simchen et al. 1972). Moreover, the substrates utilized for macromolecular synthesis are derived from internal pools or the catabolism of vegetative proteins and nucleic acids (for review, see Miller 1989). $S M K 1$ functions after the commitment point. Therefore, it is unlikely that extracellular stimuli activate the SMK1 pathway. Intracellular events that could activate Smkl include subcellular structural changes that accompany the completion of meiosis II, or the emergence of prospore autonomy. It is also possible that the $S M K 1$ pathway is a constitutively active signaling pathway controlled entirely at the level of transcription. In this scenario, the transcriptional program would be sufficient to ensure that the SMK1 pathway is active only during a precisely determined window of development. An equally enigmatic issue concerns the nature of the Smkl substrates. Candidate substrates include transcriptional 
regulators and direct regulators of the spore wall assembly pathway (see above).

\section{Timing and signaling pathways in development}

Studies of mutations affecting meiosis-specific processes have revealed that the initiation of each landmark event is not dependent on the completion of a preceding event. For example, mutations in SPO13 cause cells to bypass meiosis I and perform meiosis II resulting in two diploid spores instead of the normal four haploid products $\mid \mathrm{Kla}$ pholz and Esposito 1980). These events are not completely independent, however, because an invariant order is observed, indicating that some form of interpathway communication is present. A central unresolved issue that remains with respect to yeast sporulation in particular, and development in general, concerns the mechanisms that establish temporal order among independent events. The burst of SMK1 expression represents a level of developmental control that could coordinate the execution of independent events with the developmentally regulated program of gene expression.

\section{Materials and methods}

\section{Yeast strains and culture conditions}

The genotypes and sources of strains used in this study are shown in Table 1. Vegetative cultures were maintained on YEPD ( $1 \%$ yeast extract, $2 \%$ Bacto-peptone, $2 \%$ glucose) or on $\mathrm{SD}\{0.67 \%$ Difco yeast nitrogen base without amino acids and $2 \%$ glucose) supplemented with nutrients essential for auxotrophic strains at the levels specified by Sherman et al. (1986). Synchronous sporulation of SK1 derivatives was carried out by inoculating YEPA ( $1 \%$ yeast extract, $2 \%$ peptone, and $2 \%$ potassium acetate) with a fresh culture of logarithmic cells, expanding the culture for at least $24 \mathrm{hr}$ to a density of $1 \times 10^{7}$ cells $/ \mathrm{ml}$, collecting the cells by centrifugation, washing with $2 \%$ potassium acetate, and resuspending the cell pellet at $4 \times 10^{7}$ cells $/ \mathrm{ml}$ in $2 \%$ potassium acetate supplemented with $10 \mu \mathrm{g} / \mathrm{ml}$ of uracil. Sporulation cultures were maintained with vigorous aeration at $30^{\circ} \mathrm{C}$. Under these conditions the NKY278 control strain sporulated relatively synchronously to yield $>90 \% \mathrm{ma}-$ ture asci by $14 \mathrm{hr}$ as monitored by phase-contrast light microscopy. The sensitivity of cells to ether was determined as described by Dawes and Hardie (1974). The viability of cells after exposure to a $55^{\circ} \mathrm{C}$ heat shock or after treatment with glusulase was determined as described by Briza et al. (1990a). The ability

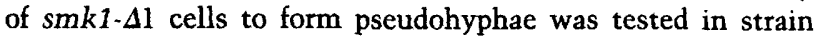
LAKY13 (Table 1) as described by Gimeno et al. (1992). The effect of $S M K 1$ on uncovering the recessive can $1^{1}$ marker following sporulation was determined by directly plating sporulated aliquots of LAKY57 or LAKY58 (Table 1) on YPD or on canavanine medium (Sherman et al. 1986).

\section{Cloning and sequencing of SMKI}

PCRs were carried out on DNA prepared from yeast strain JPHY1, which is deleted for the known MAP kinase genes FUS3, KSS1, and HOG1, as well as strains that contained intact FUS3, KSS1, or HOG1 genes as positive controls. PCR primer 1 was a degenerate oligonucleotide corresponding to the amino acid sequence V-A-I-K-K-I in subdomain II as defined by Hanks et al. (1988) and consisted of the DNA sequence 5'-GG-
AATCGTXGCXAT/T/A/C)AA/A/G)AA/A/G)AT-3' with the indicated degeneracies and where $\mathrm{X}$ designates equimolar mixtures of all 4 bases. PCR primer 2 was a nondegenerate oligonucleotide corresponding to the amino acid sequence T-R-Y-YR-A-P-E in subdomain VIII and consisted of the sequence 5'CTAGATACTACAGGGCCCCTG- ${ }^{\prime}$. PCR parameters were as described (Ausubel et al. 1987) with $30 \mathrm{sec} / 95^{\circ} \mathrm{C}$ denaturation, $60 \mathrm{sec} / 45^{\circ} \mathrm{C}$ annealing, and $60 \mathrm{sec} / 72^{\circ} \mathrm{C}$ extension times. Amplification products were digested with EcoRI and $A p a I$ and subcloned into EcoRI/SmaI-digested pUC19. Different plasmids (51) obtained in this manner that contained inserts of the appropriate sizes were isolated and their inserts determined by the Sanger chain termination method as described in Ausubel et al. (1987). Some inserts (36) were unrelated to kinase genes and presumably reflected the low stringency parameters and degeneracy of the primers used in these experiments. The remaining 15 inserts represented two kinase genes. One of these was isolated nine times independently. Partial nucleotide sequence analysis of this insert showed that it was most similar to MDS1 and other members of the glycogen synthase kinase gene family (Puziss et al. 1994). This gene has been cloned recently using a similar strategy to that described above (T.A. Hardy, D. Wu, and P.J. Roach, pers. comm.). SMK1 was isolated six times independently. The SMK1 PCR fragment was radiolabeled and used to isolate the full-length $S M K 1$ gene from a genomic library of yeast DNA contained in the EMBL $\lambda$ phage as described previously (Winter and Varshavsky 1989). A 4.0-kb KpnI fragment that was common to 10 of the 12 phage isolates and that hybridized to the SMK1 PCR fragment was subcloned into pUC19 to yield plasmid pLAK8. The nucleotide sequence of one end of the pLAK8 insert was identical to a region adjacent to the NHP6 promoter based on $273 \mathrm{bp}$ of identical sequence information (Tercero et al. 1992). This identity placed SMK1 immediately adjacent to NHP6 proximal to centromere XVI (Fig. 1). DNA from the KpnI site toward the $X$ hoI site ( $1870 \mathrm{bp}$ ) was sequenced on both strands using a nested series of overlapping unidirectional deletion constructs prepared with exonuclease VII and exonuclease III (Ausubel et al. 1987).

A 2.4-kb KpnI-Xhol fragment of pLAK8 was subcloned into the KpnI-XhoI sites of pRS316, the KpnI-SalI sites of YEP352, the KpnI-Sall sites of pUC19, and the KpnI-Sall sites of pRS314 to generate pLAK40, pLAK42, pLAK44, and pLAK51, respectively (Table 2). Searches for homology to protein sequences in the GenBank, EMBL, and SwissProt data bases were performed with the FASTA program, and the comparison of MAP kinases shown in Figure 1 was performed with the PILEUP program in the University of Wisconsin GCG analysis package. The GenBank accession number for the SMK1 sequence is L35047.

Table 2. Plasmids

\begin{tabular}{|c|c|c|}
\hline Plasmid & Markers & Reference \\
\hline pRS314 & CEN TRP1 & $\begin{array}{l}\text { Sikorski and Hieter } \\
\text { (1989) }\end{array}$ \\
\hline pLAK51 & $\mathrm{pRS} 314+S M K 1$ & this study \\
\hline Yep352 & $2 \mu+U R A 3$ & Hill et al. (1986) \\
\hline pLAK 42 & Yep352+SMK1 & this study \\
\hline pRS316 & CEN URA3 & $\begin{array}{l}\text { Sikorski and Hieter } \\
\text { (1989) }\end{array}$ \\
\hline pLAK40 & pRS316 + SMK1 & this study \\
\hline pLAK44 & pUC19 + SMK1 & this study \\
\hline pLAK46 & pUC19 + smk1- $\triangle 1:: U R A 3$ & this study \\
\hline
\end{tabular}




\section{Creation of smkl mutant strains}

The 0.8-kb StyI restriction endonuclease fragment of SMK1 that encodes amino acid residues 30-297 of the predicted Smk1 product (see Fig. 1) was replaced in pLAK44 with the BamHIgenerated URA3 fragment of YDPU (Berben et al. 1991), using DNA polymerase I to make the DNA ends flush, and T4 DNA ligase. The resulting plasmid pLAK46, which contains the $S M K 1$ and $U R A 3$ promoters in opposite orientations, was linearized with $K p n I$ and SalI and used to replace the genomic $S M K 1$ locus in diploid yeast strains as described by Rothstein (1991). Heterozygous strains were sporulated and tetrads microdissected to yield haploid products that were subsequently backcrossed to generate the homozygous smk1 strains shown in Table 1. Appropriate gene disruption events and segregation patterns were confirmed by Southern blot hybridization analysis of EcoRI-digested genomic DNA extracted from diploids and haploids using the 2.4-kb SMK1-containing KpnI-Sall fragment of pLAK40.

\section{RNA Analysis}

Cells $\left(4 \times 10^{8}\right)$ were collected by centrifugation at 2 -hr intervals after transfer to sporulation medium, and total RNA was prepared by the glass bead/phenol procedure (Ausubel et al. 1987). SPO13 mRNA levels were quantitated using $10 \mu \mathrm{g}$ of total RNA per sample by the $S 1$ nuclease protection method as described by Strich et al. (1989). For Northern hybridization analysis, RNA $(20 \mu \mathrm{g})$ was electrophoresed through a $1.4 \%$ agarose gel in $40 \mathrm{~mm}$ morpholinopropane sulfonic acid $(\mathrm{pH} 7.0), 10 \mathrm{~mm} \mathrm{Na}$ acetate, $1 \mathrm{~mm}$ EDTA, and $5 \mu \mathrm{g} / \mathrm{ml}$ of EtBr and made $1.5 \%$ with respect to formaldehyde immediately prior to casting the gel. After electrophoresis, the gel was soaked for $30 \mathrm{~min}$ in $25 \mathrm{~mm}$ $\mathrm{NaH}_{2} \mathrm{PO}_{4}-\mathrm{Na}_{2} \mathrm{HPO}_{4}$ (pH 7.0), photographed under shortwave UV illumination, and the RNA transferred to GeneScreen membrane (Dupont) overnight in $25 \mathrm{~mm} \mathrm{NaH} \mathrm{PO}_{4}-\mathrm{Na}_{2} \mathrm{HPO}_{4}$ (pH 7.0). The filter was dried at $80^{\circ} \mathrm{C}$ for $1 \mathrm{hr}$ and UV irradiated to cross-link the RNA to the membrane as recommended by the manufacturer. DNA probes were from the coding regions of the indicated genes and were isolated from preparative agarose gels and radiolabeled by random priming using the large fragment of DNA polymerase I (Ausubel et al. 1987). ${ }^{32} \mathrm{P}$-Radiolabeled DNA probe was separated from free nucleotide and used in hybridization analysis at $10^{6}$ disintegrations per minute $(\mathrm{dpm}) / \mathrm{ml}$. The following plasmids and restriction endonuclease fragments were used to measure RNA levels: $S M K 1$; the 0.8 -kb StyI fragment of pLAK44, SPO12; the 0.4-kb EcoRI-BamHI fragment of pSW-4 (Malavasic and Elder 1990), DIT1; the 2.0-kb BamHI fragment of pPB-16E (Briza et al. 1990a), SPS100; the 750-bp NcoIBamHI fragment of pE18-B8a (Law and Segall 1988). A single filter was used for all of the Northern hybridization experiments shown in Figure 5 . The filter was heated to $95^{\circ} \mathrm{C}$ in $10 \mathrm{~mm}$ Tris (pH 7.5), 1\% SDS, and $1 \mathrm{~mm}$ EDTA for $20 \mathrm{~min}$ prior to hybridization analysis to remove the radioactive material from the preceding hybridization experiment. Relative expression levels were from the sum of hybridization signals of all time points corrected for background and were measured using a PhosphorImager (Molecular Dynamics).

\section{Microscopy}

For light microscopy, cells were fixed in ethanol and stained with DAPI, as described (Sherman et al. 1986). Samples were viewed and photographed as a wet mount under phase-contrast oil immersion optics using a Nikon Optiphot equipped for epifluorescence. For electron microscopy, cells were pelleted by centrifugation and fixed in $2.5 \%$ glutaraldehyde in $0.13 \mathrm{M} \mathrm{cac}-$ odylate buffer ( $\mathrm{pH} 7.4)$. The specimens were postfixed in $1 \%$ osmium tetroxide for $1.5 \mathrm{hr}$, dehydrated through a graded series of ethanol, and embedded in Spurr low-viscosity resin. Ultrathin sections of $600 \AA$ thickness were cut, mounted on copper grids, and stained with saturated aqueous uranyl acetate and Reynold's lead citrate. Sections were viewed and photographed using a JEOL $100 \mathrm{~B}$ transmission electron microscope at $80 \mathrm{kV}$.

\section{Acknowledgments}

We thank Marisa Wagner, Alan Christensen, and Brian Reardon for helpful comments and critically reading the manuscript. We thank Dr. Jaquelline Segall for helpful discussions and for communicating results prior to publication. This work has been supported by grants GM45772, HD15822, and HD29937 from the National Institutes of Health and by a grant from the Lucille P. Markey Charitable Trust.

The publication costs of this article were defrayed in part by payment of page charges. This article must therefore be hereby marked "advertisement" in accordance with 18 USC section 1734 solely to indicate this fact.

\section{References}

Alani, E., R. Padmore, and N. Kleckner. 1990. Analysis of wildtype and rad50 mutants of yeast suggests an intimate relationship between meiotic chromosome synapsis and recombination. Cell 61: 419-436.

Ammerer, G. 1994. Sex, stress and integrity: The importance of MAP kinases in yeast. Curr. Opin. Genet. Dev. 4: 90-95.

Ausubel, F.M., R. Brent, R.E. Kingston, D.D. Moore, J.A. Smith, J.G. Seidmann, and K. Struhl, eds. 1987. Current protocols in molecular biology, John Wiley \& Sons, New York.

Berben, G., J. Dumont, V. Gilliquet, P.-A. Bolle, and F. Hilger. 1991. The YDp Plasmids: A uniform set of vectors bearing versatile gene disruption cassettes for Saccharomyces cerevisiae. Yeast 7: 475-477.

Biggs III, W.H., K.H. Zavitz, B. Diskson, A. van der Straten, D. Brunner, E. Hafen, and S.L. Zipursky. 1994. The Drosophila rolled locus encodes a MAP kinase required in the sevenless signal transduction pathway. EMBO I. 13: 1628-1635.

Brewster, J.L., T. de Valoir, N.D. Dwyer, E. Winter, and M.C. Gustin. 1993. An omosensing signal transduction pathway in yeast. Science 259: 1760-1763.

Briza, P., A. Ellinger, G. Winkler, and M. Breitenbach. 1988. Chemical composition of the yeast ascospore wall. $J$. Biol. Chem. 263: 11569-11574.

Briza, P., M. Breitenbach, A. Ellinger, and J. Segall. 1990a. Isolation of two developmentally regulated genes involved in spore wall maturation in Saccharomyces cerevisiae. Genes 4) Dev. 4: 1775-1789.

Briza, P., A. Ellinger, G. Winkler, and M. Breitenbach. 1990b. Characterization of a DL-dityrosine-containing macromolecule from yeast ascospore walls. J. Biol. Chem. 265: 1511815123.

Bnunner, D., N. Oellers, J. Szabad, W.H. Biggs III, S.L. Zipursky, and E. Hafen. 1994. A gain-of-function mutation in Drosophila MAP kinase activates multiple receptor tyrosine $\mathrm{ki}$ nase signaling pathways. Cell 76: 875-888.

Byers, B. 1981. Cytology of the yeast life cycle. In The molecular and cellular biology of the yeast Saccharomyces cerevisiae. (ed. J.N. Strathern, E.W. Jones, and J.R. Broach), pp. 59-96. Cold Spring Harbor Laboratory, Cold Spring Harbor, New York. 
Crews, C.M. and R.L. Erickson. 1993. Extracellular signals and reversible protein phosphorylation: What to Mek of it all. Cell 74: 215-217.

Dawes, I.W. and I.D. Hardie. 1974. Selective killing of vegetative cells in sporulated yeast cultures by exposure to diethyl ether. Mol. Gen. Genet. 131: 281-289.

Elion, E.A., B. Satterberg, and J.E. Kranz. 1993. FUS3 phosphorylates multiple components of the mating signal transduction cascade: Evidence for STE12 and FAR1. Mol. Biol. Cell 4:495-510.

Errede, B. and D.E. Levin. 1993. A conserved kinase cascade for MAP kinase activation in yeast. Curr. Opin. Cell Biol. 5: 254-260.

Esposito, R.E. and S. Klapholtz 1981. Meiosis and ascospore development. In The molecular and cellular biology of the yeast Saccharomyces cerevisiae. (ed. J.N. Strathern, E.W. Jones, and J.R. Broach|, pp. 211-287. Cold Spring Harbor Laboratory, Cold Spring Harbor, New York.

Gimeno, C.J., P.O. Ljundahl, C.A. Styles, and G.R. Fink. 1992. Unipolar cell divisions in yeast $S$. cerevisiae lead to filamentous growth: Regulation by starvation and RAS. Cell 68: $1077-1090$.

Hanks, S.K., A.M. Quinn, and T. Hunter. 1988. The protein kinase family: Conserved features and deduced phylogeny of the catalytic domains. Science 241: 42-52.

Hill, J.E., A.M. Myers, T.J. Koemer, and A. Tzagoloff. 1986. Yeast $E$. coli shuttle vectors with multiple unique restriction sites. Yeast 2: 163-167.

Honigberg, S.M., R.M. McCarroll, and R.E. Esposito. 1993. Regulatory mechanisms in meiosis. Curr. Opin. Cell Biol. 5: 219-225.

Irie, K., M. Takase, K.S. Lee, D.E. Levin, H. Araki, K. Matsumoto, and Y. Oshima. 1993. MKK1 and MKK2, which encode Saccharomyces cerevisiae mitogen-activated protein kinasekinase homologs, function in the pathway mediated by protein kinase C. Mol. Cell. Biol. 13: 3076-3083.

Klapholz, S. and R.E. Esposito. 1980. Recombination and chromosome segregation during the single division meiosis in spo12-1 and spo13-1 diploids. Genetics 96: 567-588.

Lange-Carter, C.A., C.M. Pleiman, A.M. Gardner, K.J. Blumer, and G.L. Johnson. 1993. A divergence in the MAP kinase regulatory network defined by MEK kinase and Raf. Science 260: 315-319.

Law, D.T.S. and J. Segall. 1988. The SPS100 gene of Saccharomyces cerevisiae is activated late in the sporulation process and contributes to spore wall maturation. Mol. Cell. Biol. 8: $912-922$

Lee, K.S., K. Irie, Y. Gotoh, Y. Watanabe, H. Araki, E. Nishida, K. Matsumoto, and D.E. Levin. 1993. A yeast mitogen-activated protein kinase homolog (Mpklp) mediates signalling by protein kinase C. Mol. Cell. Biol. 13: 3067-3075.

Liu, H., C.A. Styles, and G.R. Fink. 1993. Elements of the yeast pheromone response pathway required for filamentous growth of diploids. Science 262: 1741-1744.

Magee, P.T. 1987. Transcription during meiosis. In Meiosis (ed. P.B. Moens), pp. 335-382 Academic Press, Orlando, FL.

Malavasic, M.J. and R.T. Elder. 1990. Complementary transcripts from two genes necessary for normal meiosis in the yeast Saccharomyces cerevisiae. Mol. Cell. Biol. 10: 28092819.

Malone, R.E. 1991. Dual regulation of meiosis in yeast. Cell 61: 375-378.

Marshall, C.J. 1994. MAP kinase kinase kinase, MAP kinase kinase and MAP kinase. Curr. Opin. Genet. Dev. 4: 82-89.

Miller, J.J. 1989. Sporulation in Saccharomyces cerevisiae. In The Yeasts (ed. A.H. Rose, and J.S. Harrison), pp. 489-550.
Academic Press Limited, London, UK.

Mitchell, A.P. 1994. Control of meiotic gene expression in Saccharomyces cerevisiae: Microbiol. Rev. 58: 56-70.

Neigeborn, L. and A.P. Mitchell. 1991. The yeast MCKl gene encodes a protein kinase homolog that activates early meiotic gene expression. Genes \& Dev. 5: 533-548.

Neiman, A.M. 1993. Conservation and reiteration of a kinase cascade. Trends Genet. 3: 390-394.

Nishida, E. and Y. Gotoh. 1993. The MAP kinase cascade is essential for diverse signal transduction pathways. Trends Biochem. Sci. 18: 128-131.

Percival-Smith, A. and J. Segall. 1986. Characterization and mutational analysis of a cluster of three genes expressed preferentially during sporulation of Saccharomyces cerevisiae. Mol. Cell. Biol. 6: 2443-2451.

Peter, M., A. Gartner, J. Horecka, G. Ammerer, and I. Herskowitz. 1993. FARl links the signal transduction pathway to the cell cycle machinery in yeast. Cell 73: 747-760.

Puziss, J.W., T.A. Hardy, R.B. Johnson, P.J. Roach, and P. Hieter. 1994. MDS1, a dosage suppressor of an mck1 mutant, encodes a putative yeast homolog of glycogen synthase kinase 3. Mol. Cell. Biol. 14: 831-839.

Rothstein, R. 1991. Targeting, disruption, replacement, and allele rescue: Integrative DNA transformation in yeast. Methods Enzymol. 194: 281-301.

Sherman, F., G. Fink, and J.B. Hicks. 1986. Methods in yeast genetics: A laboratory manual. Cold Spring Harbor Laboratory, Cold Spring Harbor, New York.

Shero, J.H. and P. Hieter. 1991. A suppressor of a centromere DNA mutation encodes a putative protein kinase (MCK1). Genes \& Dev. 5: 549-560.

Shuster, E.O. and B. Byers. 1989. Pachytene arrest and other meiotic effects of the start mutations in Saccharomyces cerevisiae. Genetics 123: 29-43.

Sikorski, R.S. and P. Hieter. 1989. A system of shuttle vectors and yeast host strains designed for efficient manipulation of DNA in Saccharomyces cerevisiae. Genetics 122: 19-27.

Simchen, G., R. Pinon, and Y. Salts. 1972. Sporulation in Saccharomyces cerevisiae: Premeiotic DNA synthesis, readiness and commitment. Exp. Cell Res. 75: 297-218.

Sprague Jr., G.F. and J.W. Thorner. 1992. Pheromone response and signal transduction during the mating process of Saccharomyces cerevisiae: In The molecular and cellular biology of the yeast Saccharomyces cerevisiae. (ed. E.W. Jones, J. Pringle, and J.R. Broach), pp.657-744. Cold Spring Harbor Laboratory Press, Cold Spring Harbor, New York.

Strich, R., M.R. Slater, and R.E. Esposito. 1989. Identification of negative regulatory genes that govern the expression of early meiotic genes in yeast. Proc. Natl. Acad. Sci. 86: 1008110022.

Tercero, J.C., L.E. Riles, and R.B. Wickner. 1992. Localized mutagenesis and evidence for post-transcriptional regulation of MAK3. J. Biol. Chem. 267: 20270-20276.

Winter, E. and A. Varshavsky. 1989. A DNA binding protein that recognizes oligo $(\mathrm{dA}) \cdot$ oligo $(\mathrm{dT})$ tracts. $E M B O / .8: 1867-$ 1877. 


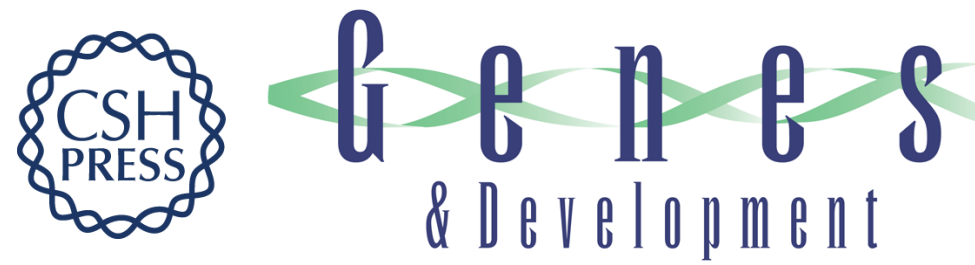

\section{SMK1, a developmentally regulated MAP kinase, is required for spore wall assembly in Saccharomyces cerevisiae.}

L Krisak, R Strich, R S Winters, et al.

Genes Dev. 1994, 8:

Access the most recent version at doi:10.1101/gad.8.18.2151

References This article cites 40 articles, 20 of which can be accessed free at:

http://genesdev.cshlp.org/content/8/18/2151.full.html\#ref-list-1

License

Email Alerting

Service

Receive free email alerts when new articles cite this article - sign up in the box at the top right corner of the article or click here.

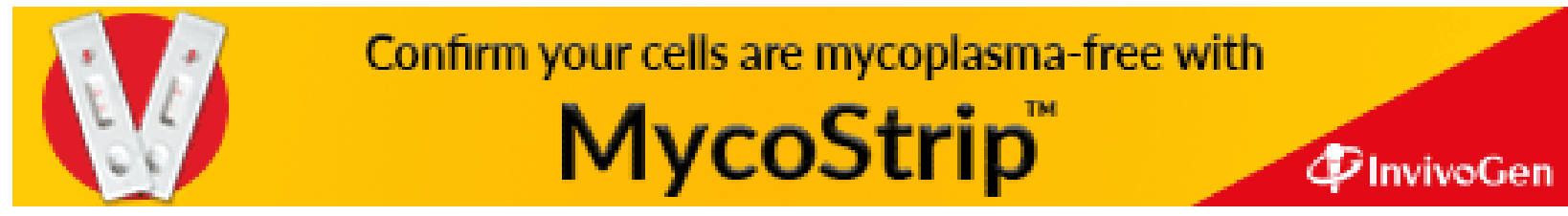

